\section{Características epidemiológicas de casos de câncer de boca registrados em hospital de Uberaba no período 1999-2003: um alerta para a necessidade de diagnóstico precoce}

\section{Epidemiological Characteristics of cases of mouth cancer registered in a hospital in the city of Uberaba from 1999-2003: a warning toward the need for early diagnosis}

\section{Graziela Cassimiro de Araújo Daher \\ Gilberto de Araújo Pereira \\ Ana Carolina D'Arelli Oliveira}

Departamento de Enfermagem em Educação e Saúde Comunitária da Universidade Federal do Triângulo Mineiro (UFTM)

Fontes de financiamento da Pesquisa: individual da própria autora com fins de execução da Monografia para conclusão do curso de Especialização em Saúde Coletiva na UFTM.

Aprovado pelo Comitê de Ética em Pesquisa da Universidade Federal do Triângulo Mineiro sob o № 799 em 10 de novembro de 2006.

Correspondência: Graziela Cassimiro de Araújo Daher, Rua Padre Zeferino, 963 Fabrício, Uberaba,

MG, CEP 38065-100. E-mail: gcaser@terra.com.br

\section{Resumo}

Foi realizado estudo de 101 casos de carcinoma epidermóide de boca registrados em Hospital de Uberaba, no período de 1999 a 2003. Informações sobre sexo, idade, cor de pele, nível instrucional, tabagismo, etilismo, uso de prótese, localização da lesão, estado da doença ao final do seguimento, estádio clínico e origem do encaminhamento foram obtidos dos prontuários e analisados estatisticamente pelos testes de correlação linear, Qui-quadrado, t-Student e KaplanMeier. A relação homem/mulher foi de 3,8:1. A faixa etária prevalente foi de 50 a 60 anos, com a idade média de 58,55 anos para o sexo masculino e 54,66 anos para o sexo feminino; $88,12 \%$ eram caucasianos. A língua foi a localização anatômica mais freqüente; $74,48 \%$ estavam nos estádios III e IV. A sobrevida em 5 anos foi de $38,71 \%$. Os baixos índices de sobrevivência e o grande percentual de estádios III e IV refletem a necessidade de uma maior atenção ao câncer bucal nessa população.

Palavras-chave: Carcinoma de células escamosas. Neoplasias da boca. Epidemiologia. 


\section{Abstract}

The authors performed a study of 101 cases of epidermoid carcinoma of the mouth registered at a Hospital in the city of Uberaba, from 1999 to 2003. Information on gender, age, skin color, schooling, smoking, alcoholism, prosthesis, site of lesion, disease outcome at the end of follow-up, clinical staging, and origin of referral were obtained from medical records. Statistical analysis was performed using linear correlation, chi-square, t-Student, and Kaplan-Meier tests. The male/female ratio was 3.8:1. The most prevalent age group was 50 to 60 years, with an average age of 58.55 years for men and 54.66 years for women; $88.12 \%$ were Caucasian. The most frequent anatomical site was the tongue and $74.48 \%$ were stages III and IV. Five-year survival was $38.71 \%$. The low rates of survival and the high percentage of stages III and IV show the need for greater attention to mouth cancer in this population.

Keywords: Squamous cell carcinoma. Mouth neoplasms. Epidemiology.

\section{Introdução}

O câncer de boca pode ser considerado o câncer mais comum da região da cabeça e pescoço, excluindo-se o câncer de pele ${ }^{1}$, sendo que cerca de 90 a 96\% dos cânceres de boca são representados pelo carcinoma epidermóide ${ }^{2}$. Pesquisas mostram que este neoplasma apresenta maior incidência em indivíduos do sexo masculino ${ }^{3,4}$, com predomínio de caucasianos ${ }^{5,6}$, manifestando-se predominantemente entre os 50 e 70 anos de idade $^{5-7}$. Os mais importantes fatores de risco conhecidos para essa neoplasia são o tabagismo e o etilismo, os quais apresentam efeitos sinérgicos no desenvolvimento do tumor $^{8} \mathrm{e}$, em .relação à dieta, ocorre uma redução do risco com o consumo freqüente de frutas cítricas e alimentos ricos em caroteno ${ }^{8}$. Em alguns autores, observa-se um crescente interesse sobre a possibilidade de agentes biológicos terem um papel na etiologia desta neoplasia, porém os estudos epidemiológicos não são conclusivos ${ }^{9}$. Os fenômenos irritativos, embora não haja estudos com comprovação conclusiva de causa-efeito, podem contribuir para o desenvolvimento do carcinoma. A irritação crônica causada pelo uso prolongado de próteses dentárias mal adaptadas, câmaras de sucção e bordas cortantes de dentes sobre a mucosa bucal por longo tempo, pode induzir o desenvolvimento do carcinoma pela potencialização de outros agentes carcinógenos, particularmente em tabagistas e etilistas, podendo-se ainda citar, como fatores irritantes, os hábitos alimentares (condimento e temperatura) e a má higiene bucal ${ }^{10}$. A exposição repetida e excessiva aos raios solares ultravioleta, por períodos superiores a 15 ou 30 anos, pode representar um considerável fator de risco para o câncer de lábio inferior, sendo que as pessoas de pele clara, com pouca pigmentação melânica, são as que apresentam o maior risco de desenvolvê-lo ${ }^{11}$.

A denominação "câncer de boca" inclui várias localizações primárias de tumor (códigos C00 a C06 da Classificação Estatística Internacional de Doenças e Problemas Relacionados à Saúde/Décima Revisão -CID 
10) ${ }^{11,12}$. Quanto à localização primária, estudos indicam que a região anatômica mais comum de envolvimento do carcinoma bucal é a língua ${ }^{3,7,13}$. Quanto ao encaminhamento, alguns autores observaram que os profissionais médicos foram os que mais encaminharam pacientes com tumores bucais e de orofaringe $\mathrm{e}^{(5,14}$.

Há um sistema de estadiamento clínico que foi desenvolvido segundo a classificação da International Union Against CancerUICC $^{15}$. Este sistema, conhecido como TNM, tem como base a avaliação da dimensão do tumor (T), a extensão da disseminação em linfonodos regionais $(\mathrm{N})$ e a presença ou não de metástase à distância $(\mathrm{M})$. A combinação das diversas variantes de $\mathrm{T}, \mathrm{N}$ e $\mathrm{M}$ determinam os estádios que variam de I a IV. A divisão de casos de câncer em grupos, de acordo com os estádios, deveu-se ao fato de as taxas de sobrevivência serem maiores nos casos em que a doença estava localizada e menores quando havia se estendido além do órgão de origem ${ }^{15}$.

O estágio avançado, muitas vezes não tratável, em que os casos chegam aos hospitais, independendo da maior ou menor complexidade de meios diagnósticos, indica a organização e o acesso a esse tratamento. O câncer de boca, de fácil diagnóstico, é próprio de pessoas de baixa renda, tabagistas e alcoólatras. Ele teria diagnóstico mais precoce, caso essas pessoas tivessem melhor instrução, melhor alimentação e maior acesso à assistência médica. Porém, se assim fosse, certamente elas não desenvolveriam câncer de boca ... ${ }^{16}$.

Em relação ao estadiamento das lesões, segundo alguns autores, aproximadamente $60 \%$ dos pacientes chegam aos hospitais especializados com o câncer de boca nos estágios III e IV, cujo tratamento torna-se mais difícil, causando, nos casos de sobrevivência, desfiguração, disfunção e trauma psicológico ${ }^{17}$.

No Brasil, o estudo da sobrevida de casos de câncer da boca tratados no Hospital Erasto Gaertner-Curitiba, no período de 1990 a 1992, mostrou que a sobrevida em 5 anos, independente do estadiamento clínico, foi de $50,1 \%{ }^{11}$.
No Brasil, para 2008, as neoplasias da cavidade oral apresentam uma estimativa de 14.160 casos para homens e mulheres, estando a região Sudeste com a maior estimativa de incidência para 2008 (cerca de 8.010 casos $^{18}{ }^{18}$ O Estado de Minas Gerais apresenta, para 2008, uma taxa estimada de 8,46 casos para cada 100.000 homens e 3,07 casos para cada 100.000 mulheres $^{18}$. A região Sudeste apresentou, no Brasil, a maior incidência de neoplasias malignas de lábio e cavidade oral, no período de 2000 a $2003^{19}$, além de ter apresentado, entre 1999 a 2003, uma das mais altas taxas de mortalidade por neoplasia maligna do lábio, cavidade oral e faringe ${ }^{20}$.

De acordo com o Ministério da Saúde, Sistema de Informações Hospitalares do SUS (SIH/SUS), Morbidade Hospitalar do SUS, por local de residência, de 1999-2003, temos as seguintes taxas de mortalidade para neoplasia maligna do lábio, cavidade oral e faringe, no período supra-citado (relacionando-se a quantidade de óbitos sobre o número de Autorizações de Internações Hospitalares- [AIH] pagas, vezes 100): a região Sudeste do Brasil apresentou taxa de mortalidade por região, de 11,34, enquanto para o Estado de Minas Gerais, verificou-se a taxa de $9,14^{20}$. Cumpre ressaltar que, na região Sul do Triângulo Mineiro, no mesmo período, o valor da taxa de mortalidade, por Macrorregional de Saúde, foi de 9,94 (valor superior ao do Norte do Triângulo Mineiro que apresentou o valor de 7,04) ${ }^{21}$. A macrorregional de Uberaba, no mesmo período, apresentou a taxa de mortalidade de $11,09^{21}$. Diante do exposto, julgou-se de interesse da saúde pública proceder um estudo epidemiológico em Uberaba-MG , no período de 1999 a 2003.

\section{Objetivos}

Descrever as características demográficas e epidemiológicas dos pacientes com diagnóstico de carcinoma epidermóide bucal no centro de referência para o tratamento de câncer em Uberaba-MG, no período de 1999 a 2003. 


\section{Métodos}

Trata-se de um estudo retrospectivo descritivo e comparativo, onde a amostra selecionada foi constituída de 101 pacientes de ambos os sexos e com idade acima de dezoito anos, atendidos com diagnóstico de carcinoma epidermóide bucal (carcinoma espinocelular bucal), no período de 1999 a 2003, no Hospital Dr. Hélio Angotti, na cidade de Uberaba no Estado de Minas Gerais. O estudo foi realizado através da coleta de dados dos prontuários e fichas de registro clínico hospitalar dos pacientes. O presente estudo teve seu projeto de pesquisa aprovado pelo Comitê de Ética em Pesquisa - CEP da Universidade Federal do Triângulo Mineiro - UFTM, sob o no 799 em 10 de novembro de 2006.

Foram levantados os seguintes dados: sexo, idade, cor da pele, grau de instrução, tabagismo, etilismo, uso de prótese, localização primária do tumor, data do diagnóstico inicial, data do último seguimento ou óbito, estado da doença até o último seguimento no hospital, estadiamento, bem como origem do encaminhamento do paciente ao tratamento. A localização primária do tumor, segundo os códigos topográficos da Classificação Internacional de Doenças $10^{\mathrm{a}}$ revisão (CID 10) incluiu: C00 (neoplasia maligna do lábio), C01 (neoplasia maligna da base da língua, C02 (neoplasia maligna de outras partes e partes não especificadas da língua, C03 (neoplasia maligna da gengiva), C04 (neoplasia maligna do assoalho da boca, C05 (neoplasia maligna do palato e C06 (neoplasia maligna de outras partes e de partes não especificadas da boca. Estes dados foram compilados para uma ficha específica (instrumento de coleta de dados) e depois passados para um banco de dados no programa Excel. Em seguida foram analisados e tratados estatisticamente.

\section{Análise estatística}

As variáveis numéricas foram analisadas através das medidas descritivas (centralidade: média, mediana e moda; Dispersão: des- vio padrão, coeficiente de variação e valor mínimo e máximo). Utilizamos freqüências absolutas e percentuais para as variáveis categóricas. Para estudar as associações entre as variáveis categóricas de interesse e também para as comparações entre os anos de 1999 e 2003 utilizamos o teste Qui-Quadrado. Para comparar as variáveis numéricas entre os sexos e entre os anos de 1999 e 2003 utilizamos o teste t-Student. O coeficiente de correlação linear foi empregado para verificar as correlações entre as variáveis numéricas de interesse. O método de Kaplan Méier foi considerado para verificar a probabilidade de sobrevivência dos pacientes após o diagnóstico.

Os resultados foram organizados em tabelas/quadros e/ou gráficos. O nível de significância para os testes foi de $=0,05$.

\section{Resultados}

De acordo com a análise dos dados referentes aos pacientes portadores de carcinoma epidermóide de boca (carcinoma espinocelular- CEC), constatamos que dos 101 casos analisados, 80 (79,2\%) foram do sexo masculino e $21(20,8 \%)$ do sexo feminino, com uma relação masculino/feminino de 3,8:1. Em relação à idade geral dos pacientes que compuseram o estudo, houve uma variação desde 19 (idade mínima) até 89 anos (idade máxima), sendo a média de 57,74 anos ( $\pm 13,44$ anos). Cerca de metade dos pacientes variaram a idade entre 19 a 58 anos (mediana) e a outra metade de 59 a 89 anos. Foi mais comum encontrar pacientes com 54 anos (moda). A amostra mostrou-se heterogênea (Coeficiente de Variação $-\mathrm{CV}=$ $23,27)$. No sexo feminino a idade média foi de 54,66 anos ( $\pm 16,76$ anos) com Coeficiente de Variação - CV = 30,66 (grupo heterogêneo) sendo que para o sexo masculino foi de 58,55 anos ( $\pm 12,42$ anos) com Coeficiente de Variação - CV = 21,21. (amostra também heterogênea). Embora sem significância estatística observamos que a freqüência de carcinoma epidermóide bucal (carcinoma espinocelular - CEC) ocorreu em idade inferior no sexo feminino. $(p=0,24)$ 
A faixa etária mais atingida foi aquela entre 50 a 69 anos (57,41\%), havendo 29 pacientes $(28,71 \%)$ na idade entre 50 a 59 anos e o mesmo número e percentual na idade entre 60 a 69 anos. Para as demais faixas etárias, observamos que 16 pacientes $(15,84 \%)$ tinham entre 40 a 49 anos, 12 pacientes $(11,88 \%)$ entre 70 a 79 anos, 8 pacientes $(7,92 \%)$ entre 30 a 39 anos e uma freqüência bem reduzida entre 19 a 29 anos ( 2 pacientes ou $1,98 \%$ ) e entre 80 a 89 anos (5 pacientes ou 4,95\%). Em relação à cor da pele, observamos que 89 pacientes $(88,12 \%)$ eram brancos, 4 pacientes $(3,96 \%)$ eram pardos e 8 pacientes $(7,92 \%)$ eram negros.

Analisando o total da amostra quanto à instrução, verificamos que 16 pacientes (15,84\%) não tinham nenhuma instrução, 65 pacientes $(64,36 \%)$ tinham o $1^{\circ}$ grau incompleto, 8 (7,92\%) tinham o $1^{\circ}$ grau completo, $11(10,89 \%)$ tinham o $2^{\circ}$ grau ou mais e, um paciente $(0,99 \%)$ não possuía informação da instrução no respectivo prontuário.

A informação sobre o tabagismo não estava preenchida em 54 (53,47\%) prontuários, 38 (37,62\%) eram tabagistas e $9(8,91 \%)$ não eram tabagistas.

Sobre o etilismo havia ausência de informação em 66 (65,35\%) prontuários, 27 $(26,73 \%)$ eram etilistas e 8 (7,92\%) não.

Com relação ao uso de prótese dentária, não foi encontrada informação em 100 prontuários (99\%). Em um prontuário $(0,99 \%)$ constava a informação sobre o uso de prótese dentária, sem especificação desta, mas com relato de traumatismo.

Quanto ao sítio primário, o mais acometido foi a língua com 34 casos (33,66\%), seguido de assoalho com 21 casos $(20,79 \%)$ e base da língua com 16 casos $(15,84 \%)$. Os outros 30 casos $(29,71 \%)$ abrangeram, respectivamente, palato com 11 casos (10,90\%), lábio com 7 casos ou 6,93\% (5 neoplasias malignas de lábio inferior, um caso de lábio, não especificado e um caso de lábio externo, não especificado), gengiva com 2 casos (1,98\%), outras partes e partes não especificadas da boca com 10 casos $(9,90 \%)$. Quanto ao estado da doença até o último seguimento, verificamos que $46,53 \%$ foram a óbito, $12,87 \%$ estavam com a doença estável, 8,91\% tinham a doença em estado de progressão, 8,91\% estavam curados, 5,94\% estavam em remissão parcial da doença e $16,83 \%$ não possuíam informação quanto ao estado da doença ao final do tratamento.

Em relação ao estadiamento, foram encontradas informações dos estádios em 98 prontuários, sendo que os estádios mais encontrados foram: estádio 3 (T3 ) com 31,63\% (31 casos) e estádio 4 (T4 ) com 42,85\% (42 casos), com T3 e T4 perfazendo juntos um total de $74,48 \%$ (74 casos).

Do total da amostra não foram encontradas informações sobre a origem do encaminhamento em $58,41 \%$ (59 prontuários), sendo que dos 42 prontuários em que constavam a informação, em 2,97\% o paciente foi por si mesmo procurar o atendimento, $33,66 \%$ foram encaminhados por profissionais médicos, enquanto $4,95 \%$ foram referenciados por cirurgiões-dentistas. Quanto à instituição encaminhadora, verificamos que: $61,38 \%$ foram encaminhados por instituições públicas, $22,77 \%$ por instituições privadas, $2,97 \%$ procuraram o tratamento por si mesmos e em $12,87 \%$ não constava a informação no prontuário.

Considerando a amostra de $82 \mathrm{pa}$ cientes, em que constava informação do estadiamento e origem do encaminhamento, verificou-se não existir diferença significativa na distribuição dos pacientes segundo o estadiamento clínico e o tipo de encaminhamento (privado ou público) $\left(\chi^{2}=\right.$ $5,60 ; p=0,13)$, embora tenha sido verificado que os estadiamentos 3 e 4 (T3 e T4) foram mais ocorrentes nos encaminhamentos de instituição pública, 36,06\% e 45,90\%, respectivamente. Já os encaminhamentos das instituições privadas foram distribuídos de forma semelhantes entre os estádios (Tabela 1).

Para a amostra de 37 pacientes, em que constava a informação do estadiamento e a origem do encaminhamento profissional, não foi possível aplicarmos o teste quiquadrado devido às freqüências baixas e nulas, porém observamos que os estádios T3 e T4 foram mais ocorrentes nos encaminha- 
Tabela 1 - Distribuição dos pacientes com carcinoma epidermóide bucal (CEC bucal) segundo a origem do encaminhamento (instituição pública ou privada) e o estadiamento da doença. Uberaba, 2007.

Table 1 - Distribution of patients with buccal squamous cell carcinoma according to the referring source (public or private institution) and clinical staging of the disease, Uberaba, 2007

\begin{tabular}{lcccccccccc}
\hline & \multicolumn{1}{c}{} & \multicolumn{4}{c}{ Estadiamento } & \multicolumn{3}{c}{ TOTAL } \\
& \multicolumn{1}{c}{ T1 } & \multicolumn{2}{c}{ T2 } & \multicolumn{2}{c}{ T3 } & \multicolumn{2}{c}{ T4 } & \multicolumn{2}{c}{ No. } \\
\hline Origem Encaminhamento & No. & $\%$ & No. & $\%$ & No. & $\%$ & No. & $\%$ & No. & $\%$ \\
Pública & 5 & 8,20 & 6 & 9,84 & 22 & 36,06 & 28 & 45,90 & 61 & 100,0 \\
Privada & 5 & 23,80 & 4 & 19,04 & 6 & 28,60 & 6 & 28,60 & 21 & 100,0 \\
Total & 10 & - & 10 & - & 28 & - & 34 & - & 82 & - \\
\hline
\end{tabular}

$\left(\chi^{2}=5,60 ; p=0,13\right) ;$ CEC: Carcinoma espinocelular (epidermóide), T1:estádio 1, T2: estádio 2, T3: estádio 3 e T4: estádio 4.

Fonte: Prontuários dos pacientes com CEC bucal, período de 1999 a 2003, do Hospital Dr Hélio Angotti de Uberaba - MG, Brasil

\#Excluídos 3 pacientes que procuraram o serviço por si próprios, 3 pacientes que não tinham informação do estadiamento e 13 pacientes que não tinham informação acerca da origem encaminhamento instituição.

$\left(\chi^{2}=5.60 ; p=0.13\right) ; C E C:$ oral squamous cell carcinoma, T1: stage 1, T2: stage 2, T3: stage 3, T4: stage 4 .

Source: Medical files of patients with buccal squamous cell carcinoma, from 1999 to 2003, Hospital Dr Hélio Angotti in Uberaba-MG,Brazil

\#Excluded 3 patients that sought the service themselves, 3 patients without information on clinical staging and 13 patients without information concerning the referring institution

Tabela 2 - Distribuição dos pacientes com CEC bucal segundo a origem do encaminhamento (médico ou cirurgião dentista) e o estadiamento da doença. Uberaba, 2007.

Table 2 - Distribution of patients with buccal squamous cell carcinoma according to referring source (medical professional or dentist) and clinical staging of the disease, Uberaba, 2007

\begin{tabular}{|c|c|c|c|c|c|c|c|c|c|c|}
\hline \multirow[b]{3}{*}{ Origem Encaminhamento } & \multicolumn{8}{|c|}{ Estadiamento } & \multirow{2}{*}{\multicolumn{2}{|c|}{ TOTAL }} \\
\hline & \multicolumn{2}{|c|}{ T1 } & \multicolumn{2}{|c|}{ T2 } & \multicolumn{2}{|c|}{ T3 } & \multicolumn{2}{|c|}{$\mathrm{T} 4$} & & \\
\hline & No. & $\%$ & No. & $\%$ & No. & $\%$ & No. & $\%$ & No. & $\%$ \\
\hline Médico & 1 & 3,12 & 0 & 0,0 & 13 & 40,63 & 18 & 56,25 & 32 & 100,0 \\
\hline Cirurgião Dentista & 2 & 40,0 & 1 & 20,0 & 1 & 20,0 & 1 & 20,0 & 5 & 100,0 \\
\hline Total & 3 & - & 1 & - & 14 & - & 19 & - & 37 & - \\
\hline \multicolumn{11}{|c|}{$\begin{array}{l}\text { CEC: Carcinoma espinocelular (epidermóide),T1:estádio 1,T2: estádio 2,T3: estádio } 3 \text { e T4: estádio } 4 . \\
\text { Fonte: Prontuários dos pacientes com CEC bucal, período de } 1999 \text { a 2003, do Hospital Dr Hélio Angotti de Uberaba - MG,Brasil } \\
\text { \# Excluídos: } 2 \text { casos em que não havia informação sobre o estadiamento, } 3 \text { casos em que os pacientes procuraram atendimento por si próprios e } 59 \text { casos } \\
\text { em que não havia informação sobre a origem do encaminhamento profissional) } \\
\text { CEC: oral squamous cell carcinoma, T1: stage 1,T2: stage 2,T3: stage 3, T4: stage 4. } \\
\text { Source: Medical files of patients with buccal squamous cell carcinoma, } 1999 \text { to 2003, Hospital Dr Hélio Angotti in Uberaba-MG, Brazil }\end{array}$} \\
\hline
\end{tabular}

mentos dos profissionais médicos, $40,63 \% \mathrm{e}$ $56,25 \%$, respectivamente (Tabela 2).

Para a amostra de 81 pacientes, em que constavam informações sobre o estadiamento e o estado da doença até o último seguimento, observou-se que a maior parte dos pacientes que tiveram remissão completa se concentrou no estádio T1 $(55,55 \%)$, enquanto a maioria daqueles que foram a óbito estava no estádio T4 (63,04\%) (Tabela 3).

Quando relacionamos os sítios primários segundo o estado da doença até o último seguimento, não foi possível a aplicação do teste qui-quadrado, pois o mesmo não pode ser aplicado com freqüências baixas e nulas. Entretanto, os resultados mostraram que para os sítios da orofaringe (base da língua e palato mole) houve maior percentual de óbitos (73,68\%/ 14 pacientes) em relação aos sítios da cavidade oral $(50,76 \% / 33$ pacientes) (Tabela 4).

Para a amostra de 97 pacientes em que constava a informação do nível de instrução e o estadiamento clínico, observou-se que não houve diferença significativa entre os pacientes do "nível sem instrução + $1^{\circ}$ grau 
Tabela 3 - Distribuição dos pacientes com CEC bucal segundo o estadiamento e o estado da doença até o último seguimento. Uberaba, 2007.

Table 3 - Distribution of patients with buccal squamous cell carcinoma according to clinical staging of the disease and the state of the disease at the end of follow-up, Uberaba, 2007

\begin{tabular}{|c|c|c|c|c|c|c|c|c|c|c|}
\hline \multirow[b]{3}{*}{ Estado da Doença } & \multicolumn{8}{|c|}{ Estadiamento } & \multirow{2}{*}{\multicolumn{2}{|c|}{ TOTAL }} \\
\hline & \multicolumn{2}{|c|}{$\mathrm{T} 1$} & \multicolumn{2}{|c|}{$\mathrm{T} 2$} & \multicolumn{2}{|c|}{ T3 } & \multicolumn{2}{|c|}{ T4 } & & \\
\hline & No. & $\%$ & No. & $\%$ & No. & $\%$ & No. & $\%$ & No. & $\%$ \\
\hline R.Completa & 5 & 55,55 & 2 & 22,22 & 2 & 22,22 & - & - & 9 & 100,0 \\
\hline R.Parcial & 2 & 33,33 & 1 & 16,66 & 2 & 33,33 & 1 & 16,66 & 6 & 100,0 \\
\hline Estável & 3 & 25,0 & 1 & 8,33 & 4 & 33,33 & 4 & 33,33 & 12 & 100,0 \\
\hline Em Progressão & - & - & 2 & 25,0 & 2 & 25,0 & 4 & 50,0 & 8 & 100,0 \\
\hline Óbito & - & - & 4 & 8,69 & 13 & 28,26 & 29 & 63,04 & 46 & 100,0 \\
\hline Total & 10 & - & 10 & - & 23 & - & 38 & - & 81 & - \\
\hline
\end{tabular}

CEC: Carcinoma espinocelular (epidermóide). R.Completa: Remissão Completa. R.Parcial: Remissão Parcial.T1:estádio 1,T2: estádio 2, T3: estádio 3 e T4: estádio 4.

Fonte: Prontuários dos pacientes com CEC bucal, período de 1999 a 2003, do Hospital Dr Hélio Angotti de Uberaba - MG, Brasil

\# Excluídos: 17 casos em que não havia informação sobre o estado da doença ao final do último seguimento e 3 casos sem informação do estadiamento. CEC: oral squamous cell carcinoma. R. Completa:Complete Remission. R. Parcial: Partial Remission.

T1: stage 1, T2: stage 2, T3: stage 3, T4: stage 4.

Source: Medical files of patients with buccal squamous cell carcinoma, 1999 to 2003, Hospital Dr Hélio Angotti in Uberaba - MG, Brazil

\#Excluded: 17 cases without information on the state of the disease at the end of follow-up time and 3 cases without information on clinical staging.

Tabela 4 - Distribuição dos pacientes com CEC bucal segundo os sítios primários e o estado da doença até o último seguimento. Uberaba, 2007.

Table 4 - Distribution of patients with buccal squamous cell carcinoma according to the primary location and the state of the disease at the end of follow-up time, Uberaba, 2007.

\begin{tabular}{|c|c|c|c|c|c|c|c|c|c|c|c|c|}
\hline \multirow[b]{3}{*}{ Sítio } & \multicolumn{10}{|c|}{ Estado da Doença } & \multirow{2}{*}{\multicolumn{2}{|c|}{ Total }} \\
\hline & \multicolumn{2}{|c|}{ R.Total } & \multicolumn{2}{|c|}{ R.Parcial } & \multicolumn{2}{|c|}{ Estável } & \multicolumn{2}{|c|}{ Progressão } & \multicolumn{2}{|c|}{ Óbitos } & & \\
\hline & No. & $\%$ & No. & $\%$ & No. & $\%$ & No. & $\%$ & No. & $\%$ & No. & $\%$ \\
\hline$A$ & 2 & 33,3 & - & - & 1 & 16,66 & 1 & 16,66 & 2 & 33,33 & 6 & 100,0 \\
\hline B & - & - & 1 & 6,66 & 2 & 13,33 & 1 & 6,66 & 11 & 73,33 & 15 & 100,0 \\
\hline C & 7 & 25,93 & 1 & 3,70 & 4 & 14,81 & 1 & 3,7 & 14 & 51,85 & 27 & 100,0 \\
\hline D & - & - & - & & 2 & 100,0 & - & - & - & - & 2 & 100,0 \\
\hline $\mathrm{E}$ & - & - & 1 & 6,25 & 3 & 18,75 & 1 & 6,25 & 11 & 68,75 & 16 & 100,0 \\
\hline $\mathrm{F}$ & - & - & 1 & 20,0 & - & - & 1 & 20,0 & 3 & 60,0 & 5 & 100,0 \\
\hline G & - & - & - & - & - & - & 1 & 25,0 & 3 & 75,0 & 4 & 100,0 \\
\hline $\mathrm{H}$ & - & - & 2 & 22,22 & 1 & 11,11 & 3 & 33,33 & 3 & 33,33 & 9 & 100,0 \\
\hline Total & 9 & & 6 & - & 13 & - & 9 & - & 47 & - & 84 & - \\
\hline
\end{tabular}

A:Lábio, B: Base da língua, C:Língua, D: Gengiva, E: Assoalho, F: Palato duro, G: Palato mole, H: Outras partes e partes não especificadas da boca. CEC:Carcinoma espinocelular (epidermóide).

Fonte: Prontuários dos pacientes com CEC bucal, período de 1999 a 2003, do Hospital Dr Hélio Angotti de Uberaba - MG, Brasil

\#Excluidos 17 pacientes, os quais não havia informação do estado da doença no último seguimento.

A: Lip, B: Base of the tongue, C: tongue, D: Gum, E: floor, F: Hard palate, G: Soft palate, H: Other parts and parts not specified of the mouth. CEC: oral squamous cell carcinoma

Source: Medical files of patients with buccal squamous cell carcinoma, 1999 to 2003, Hospital Dr Hélio Angotti in Uberaba-MG, Brazil

\#Excluded 17 patients without information on the state of the disease at the end of follow-up.

incompleto" com os estádios T3/T4 $\left(\chi^{2}=\right.$ $6,38 ; \mathrm{p}=0,38)$, observando-se, porém, uma tendência de aumento do número de indivíduos com $1^{\circ}$ grau incompleto nos estádios mais avançados da doença (Tabela 5).
Dos 101 pacientes, $90,09 \%$ (91) tiveram seu primeiro diagnóstico no período entre 1999 e 2003. Observou-se uma tendência decrescente, embora sem significância, da porcentagem de pacientes do sexo femi- 
Tabela 5 - Distribuição dos pacientes com CEC bucal, segundo o nível de instrução e o estadiamento, Uberaba, 2007. Table 5 - Distribution of patients with buccal squamous cell carcinoma, according to schooling and clinical staging, Uberaba, 2007

\begin{tabular}{|c|c|c|c|c|c|c|c|c|c|c|}
\hline \multirow[b]{3}{*}{ Nível Instrução } & \multicolumn{8}{|c|}{ Estadiamento } & \multirow{2}{*}{\multicolumn{2}{|c|}{ TOTAL }} \\
\hline & \multicolumn{2}{|c|}{$\mathrm{T} 1$} & \multicolumn{2}{|c|}{$\mathrm{T} 2$} & \multicolumn{2}{|c|}{ T3 } & \multicolumn{2}{|c|}{$\mathrm{T} 4$} & & \\
\hline & No. & $\%$ & No. & $\%$ & No. & $\%$ & No. & $\%$ & No. & $\%$ \\
\hline A & 7 & 8,75 & 11 & 13,75 & 25 & 31,25 & 37 & 46,25 & 80 & \\
\hline B & 2 & 25,0 & 1 & 12,5 & 2 & 25,0 & 3 & 37,5 & 8 & 100,0 \\
\hline C & 3 & 33,33 & 1 & 11,11 & 3 & 33,33 & 2 & 22,22 & 9 & 100,0 \\
\hline Total & 12 & - & 13 & - & 30 & - & 42 & - & 97 & - \\
\hline
\end{tabular}

$\left(\chi^{2}=6,38 ; p=0,38\right) ; A:$ Sem instrução+1 $1^{\circ}$.grau incompleto, B: $1^{\circ}$.grau completo, $C: 2^{\circ}$. grau ou mais, CEC: Carcinoma espinocelular (epidermóide).

Fonte: Prontuários dos pacientes com CEC bucal, período de 1999 a 2003, do Hospital Dr Hélio Angotti de Uberaba-MG-Brasil \#Excluidos 3 casos sem informação do estadiamento e 1 caso sem informação do nível de instrução.

$\left(\chi^{2}=6.38 ; p=0.38\right) ; A$ : No schooling+ incomplete elementary school, B: complete elementary school, C: high school or above. CEC: oral squamous cell carcinoma Medical files of patients with buccal squamous cell carcinoma, 1999 to 2003, Hospital Dr Hélio Angotti in Uberaba-MG, Brazil:

\#Excluded 3 cases without information on the clinical staging and 1 case without information on schooling.

nino, no período de 1999 a 2003. $(r=-0,86$; $\mathrm{p}=0,06)$ enquanto no sexo masculino esta tendência mostrou-se crescente $(r=$ $+0,23 ; p=0,71$ ), também sem significância estatística. Observou-se que a tendência decrescente (diminuição) no sexo feminino foi mais evidente do que a tendência crescente (aumento) no sexo masculino, no

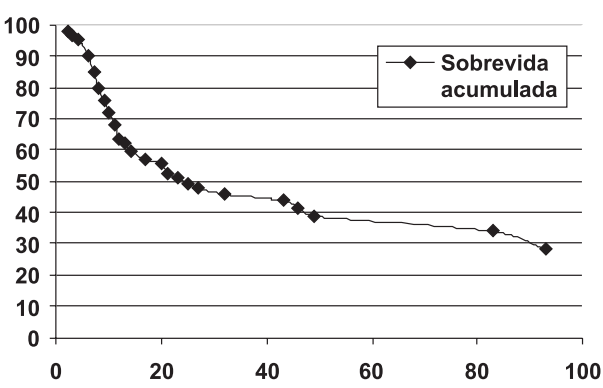

Figura 1 - Probabilidade de sobrevida acumulada para os pacientes com CEC bucal atendidos no Hospital Dr Hélio Angotti, no periodo de 1999 a 2003 (método de KaplanMeier).

Fonte: Prontuários dos pacientes com CEC bucal, período de 1999 a 2003, do Hospital Dr Hélio Angotti de Uberaba - MG, Brasil

Figure 1 - Probability of accumulated survival for the patients with buccal squamous cell carcinoma seen at Hospital Dr Hélio Angotti, from 1999 to 2003 (method of Kaplan-Meier). Source: Medical files of patients with buccal squamous cell carcinoma, 1999 to 2003, Hospital Dr Hélio Angotti in Uberaba - MG, Brazil mesmo período.

Em relação à sobrevida global, esta foi calculada a partir do diagnóstico até o último seguimento ou óbito do paciente. Dos 17 pacientes (os quais não havia informação do estado da doença ao final do tratamento no hospital), 15 foram censurados na última data de presença no hospital e 2 pacientes foram excluídos por não darem seguimento. Também foram excluídos 6 pacientes, cuja informação do estado constou na primeira alta, porém não deram nenhum seguimento, e 2 pacientes cuja data do óbito não constava nos registros. A taxa global de sobrevida em 5 anos foi de $38,71 \%$, ou seja, para os pacientes com carcinoma epidermóide de boca deste estudo, a probabilidade de sobrevivência após 5 anos foi de 38,71\%, e o tempo mediano de sobrevivência foi de 23 meses (Figura 1).

Analisando-se a probabilidade de sobrevida acumulada dos pacientes de acordo com os estádios clínicos, verifica-se que há grande diferença nos resultados de sobrevida, bem melhor nos estádio I, onde não se verifica nenhum óbito. Após 5 anos, observa-se que a taxa de sobrevida dos pacientes no estádio T2 foi de $59,65 \%$, para o estádio T3 foi de $41,64 \%$ e para o estádio T4 foi de $23,93 \%$ (Figura 2).

A probabilidade de sobrevivência acumulada para os pacientes encaminhados por instituições públicas de saúde ficou 


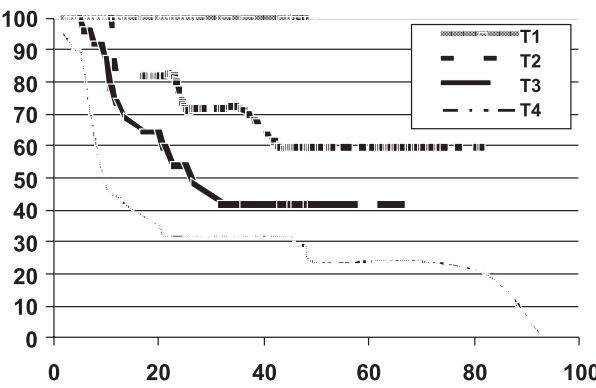

Figura 2 - Probabilidades de sobrevida segundo o estadiamento clínico para os pacientes com CEC bucal. Período de 1999 a 2003 (método de Kaplan-Meier).

Fonte: Prontuários dos pacientes com CEC bucal, período de 1999 a 2003, do Hospital Dr Hélio Angotti de Uberaba - MG, Brasil

Figure 2 - Survival probabilities according to clinical staging for patients with buccal squamous cell carcinoma, 1999 to 2003 (KaplanMeier method).

Source: Medical files of patients with buccal squamous cell carcinoma, 1999 to 2003, Hospital Dr Hélio Angotti in Uberaba-MG, Brazil

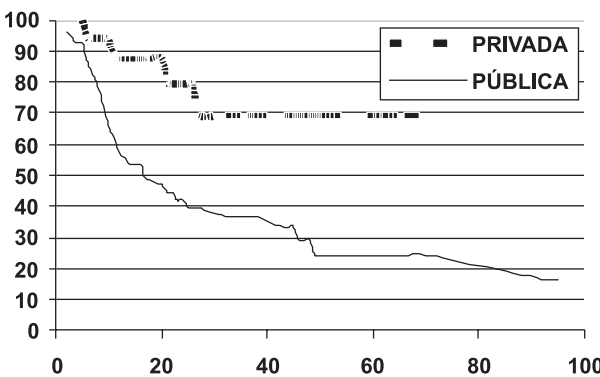

Figura 3 - Probabilidades de sobrevida segundo o encaminhamento da instituição para os pacientes com CEC bucal. Periodo de 1999 a 2003 (método de Kaplan-Meier). Fonte: Prontuários dos pacientes com CEC bucal, período de 1999 a 2003, do Hospital Dr Hélio Angotti de Uberaba - MG, Brasil Figure 3 - Survival probabilities according to referring source (institution) for patients with buccal squamous cell carcinoma, 1999 to 2003 (Kaplan-Meier method). Source: Medical files of patients with buccal squamous cell carcinoma, 1999 to 2003, Hospital Dr Hélio Angotti in Uberaba - MG, Brazil

bem abaixo do índice para os encaminhados da rede privada de saúde. Após 5 anos, a probabilidade de sobrevivência para os encaminhados da rede privada foi de $69,51 \%$, enquanto na rede pública o dado foi de $24,53 \%$ (Figura 3 ).

A estimativa da probabilidade de sobrevida em relação ao encaminhamento profissional (médico e cirurgião-dentista) não foi possível devido ao pequeno número de eventos, o que não permite uma análise evolutiva a partir do encaminhamento profissional.

\section{Discussão}

Em relação ao sexo, nossos resultados estão de acordo com outros estudos ${ }^{3,4,7,13}$ que relatam a ocorrência do carcinoma epidermóide em proporção superior no sexo masculino em relação ao feminino. Quanto à idade, na maioria das pesquisas a média encontrada no sexo feminino é maior do que no masculino ${ }^{6,7,13}$. Em nosso trabalho foi encontrada uma idade média inferior no sexo feminino que, embora sem significância estatística, demonstrou uma ocorrência mais precoce do carcinoma bucal nas mulheres no período estudado.

As faixas etárias mais atingidas em nosso estudo corresponderam às $5^{\mathrm{a}}$ e $6^{\mathrm{a}}$ décadas da vida, o que condiz com outros estudos ${ }^{4,5}$. Outros autores encontraram um aumento da incidência na $6^{\mathrm{a}}$ década da vida ${ }^{7,13}$.

Quanto à cor da pele dos pacientes, nossos resultados estão de acordo com outros autores ${ }^{5,22}$, pois verificamos que a maior parte da nossa amostra $(88,12 \%)$ era constituída de pacientes caucasianos.

Quando analisamos a instrução, verificamos que a maior parte da amostra está representada por pacientes com $1^{\circ}$ grau incompleto $(64,36 \%)$, seguido de pacientes sem nenhuma instrução $(15,84 \%)$, o que demonstra similaridade com outros trabalhos ${ }^{6}$, cuja maior parte da população de estudo estava representada por analfabetos e indivíduos com até a $8^{\mathrm{a}}$ série. Em nosso estudo, observamos que, à medida que o estádio aumenta, ocorre também aumento da proporção de indivíduos com $1^{\circ}$ grau incompleto. Em nossa amostra não foram encontrados analfabetos nos estádios I e II. 
Em outra pesquisa ${ }^{9}$, em análise de declarações de óbito por câncer de boca no Rio de Janeiro, foi encontrada ocorrência de um alto percentual $(75,5 \%)$ de indivíduos com escolaridade até o $1^{\circ}$ grau.

Em nosso estudo verificou-se que, dos registros que continham informação sobre tabagismo e/ou etilismo, a maior parte dos pacientes era constituída por tabagistas $(80,85 \%)$ e etilistas $(77,14 \%)$. Estes achados, quanto ao maior incremento de pacientes tabagistas e etilistas, corrobora os de outros autores ${ }^{5}$, cuja maior parte das amostras era constituída de tabagistas e etilistas. Em nosso estudo foi encontrada informação sobre uso de prótese em apenas um prontuário e, do total de 101 pacientes, havia $47 \mathrm{com}$ informação sobre tabagismo e 35 com informação de etilismo. Em outros trabalhos ${ }^{22}$, os autores pesquisaram hábitos de tabagismo / etilismo em 85 pacientes com Carcinoma epidermóide bucal e não encontraram estas informações em 61 casos. Com base nesses dados, devemos ressaltar a importância da coleta de informações em prontuários para contribuição em pesquisas posteriores.

Em relação à localização primária, encontramos como o sítio de maior freqüência a língua, o que está de acordo com outros trabalhos ${ }^{3,7,13}$. A segunda localização de maior freqüência encontrada em nossa pesquisa foi o assoalho da boca. Num estudo realizado em Natal- $\mathrm{RN}^{4}$, os pesquisadores encontraram como o sítio de maior incidência, o lábio, seguido de língua e assoalho. Em um outro estudo, no Estado de Sergipe $^{13}$, o lábio foi a segunda localização mais encontrada. Em relação a uma maior ocorrência de câncer de lábio na região Nordeste, estes autores ${ }^{13}$ consideram que o carcinoma do lábio inferior pode ter sua origem relacionada com a exposição dessa região anatômica à radiação solar, que é abundante no Nordeste. Numa pesquisa realizada no Estado de São Paulo ${ }^{5}$, os autores não encontraram casos de câncer de lábio. Segundo eles, deve-se considerar que boa parte dos tumores de lábio, principalmente os mais precoces, seja referenciada aos cirurgiões plásticos, não tendo uma maior representatividade em um serviço eminentemente oncológico. Esta hipótese também poderia explicar o pequeno número de casos de câncer de lábio encontrado em nossa pesquisa. O estádio mais encontrado em nossa pesquisa foi o T4, da mesma forma que em outra pesquisa ${ }^{4}$ para CEC oral, sendo que em nossa pesquisa foi encontrado grande percentual de óbitos no estádio T4. O município de Uberaba está situado na região Sudeste, que tem apresentado maior incidência para as neoplasias da cavidade oral ${ }^{18}$, lembrando aqui que, no período de 2000 a 2003, esta região apresentou uma das maiores taxas de incidência para câncer da cavidade oral ${ }^{19}$, além de uma das maiores taxas de mortalidade no período de 1999 a $2003^{20}$. Nossos achados mostraram que, do total de nossa amostra, $45,54 \%$ dos casos (46 pacientes) foram a óbito. Cerca de $74,48 \%$ da amostra eram constituídos de pacientes nos estádios mais avançados ( T3 e T4), sendo que, do total de óbitos, $63,04 \%$ correspondiam ao estádio T4, $28,26 \%$ ao estádio T3 e 8,69\% estavam no estádio T2, não sendo encontrado nenhum registro de óbito para os que estavam no estádio T1.

Em nossa pesquisa, a probabilidade de sobrevivência para aqueles pacientes em estádios avançados diminuiu à medida que se aumentou o estádio e após 5 anos do diagnóstico essas taxas foram: 59,65\% (para T2), 41,64\% (para T3) e 23,93\% (para T4), demonstrando-se mais uma vez, portanto, a necessidade de detecção precoce do carcinoma epidermóide da boca.

Alguns autores notaram que os tumores de orofaringe provocam mais óbitos do que os da cavidade bucal ${ }^{5}$. Em nosso estudo observamos que, para os sítios da orofaringe (base da língua e palato mole), houve maior percentual de óbitos $(73,68 \%)$ em relação aos sítios da cavidade oral (50,76\%), podendo sugerir que, devido à localização anatômica mais posterior, o carcinoma orofaríngeo pode ficar oculto por mais tempo, retardando o diagnóstico. Quanto à origem do encaminhamento profissional, observamos serem os profissionais médicos os que mais encaminharam pacientes. Nossos 
resultados corroboram outros resultados ${ }^{5,14}$, em que os autores encontraram também a maior proporção de seus pacientes sendo referendados por profissionais médicos, com poucos encaminhamentos de cirurgiões-dentistas. Segundo alguns autores ${ }^{23}$, as manifestações orais de neoplasias de cabeça e pescoço deveriam ser identificadas precocemente, através de exames periódicos com um cirurgião-dentista. Estes autores, avaliando a participação de cirurgiões-dentistas no diagnóstico e encaminhamento de pacientes com câncer bucal, constataram pouca participação destes. Em nossa pesquisa, dos encaminhados por cirurgiões-dentistas, $60 \%$ ( 3 pacientes) estavam nos estádios T1 e T2 e 40\% (2 pacientes) estavam nos estádios T3 e T4. No que tange ao encaminhamento médico, a maior parte dos referenciados por médicos se concentrava nos estádios T3 e T4. Cerca de $96,88 \%$ dos referenciados por médicos estavam nos estádios T3 $(40,63 \%)$ e T4 (56,25\%). Em um estudo sobre os fatores de retardo no diagnóstico clínico histológico de neoplasias malignas de cabeça e pescoço ${ }^{14}$, foi observado que os exames subsidiários e o número de outros profissionais a quem o paciente foi encaminhado foram variáveis que contribuíram para o aumento de atraso do tempo profissional, este contado desde a primeira consulta até o diagnóstico. Segundo alguns autores ${ }^{24}$, a evolução oligossintomática, o reduzido conhecimento sobre a doença entre pacientes e profissionais, $\mathrm{o}$ medo do diagnóstico e as dificuldades ao acesso médico figuram como causas importantes no atraso do diagnóstico. Neste estudo, observamos que nos encaminhamentos da rede pública de saúde houve maior prevalência percentual dos casos com estádios T3 e T4. Em nossa pesquisa, os baixos índices de sobrevida encontrados para os encaminhados pela rede pública de saúde após 5 anos (24,53\%) demonstram a necessidade de maior atenção ao carcinoma epidermóide bucal nessa população. Após 5 anos do diagnóstico, estas chances de sobrevivência para os encaminhados da rede pública se mostraram inferiores às chances de sobrevida dos encaminhados da rede privada $(69,51 \%)$. No Brasil, o encaminhamento feito pelo serviço de saúde pública para o tratamento cirúrgico de cabeça e pescoço envolve duas etapas. Primeiramente, o médico encaminha o paciente para o hospital, e secundariamente o paciente tem que marcar uma consulta com um especialista $^{3}$. Alguns autores ${ }^{25}$, avaliando o tempo decorrente entre o momento que uma lesão maligna é detectada até o início do tratamento, observaram que, a partir da detecção da lesão, o paciente é encaminhado por vários profissionais da área da saúde antes que ele seja encaminhado a um centro especializado e, por causa disso, frequentemente os pacientes apresentam lesões avançadas já causando morbidade e severas alterações no prognóstico e na qualidade de vida. Em outro trabalho ${ }^{26}$ foram avaliados os resultados da campanha de prevenção e diagnóstico precoce de câncer bucal em São Paulo e observado que a baixa resolutividade decorreu não apenas de aspectos específicos relacionados aos procedimentos de rastreamento, mas também da frágil organização dos serviços de saúde em algumas regiões do Estado, refletindo falhas no sistema de referência e contra-referência. Em outro trabalho ${ }^{3}$, os autores observaram um longo tempo de demora entre os primeiros sintomas dos pacientes até o início do tratamento destes, observando-se a necessidade de se melhorar os programas de educação em saúde pública para promoção da identificação precoce do câncer de boca. Nossos resultados, os quais demonstram poucos encaminhamentos de cirurgiõesdentistas, além de estádios avançados para encaminhados por profissionais médicos e instituições públicas, sugerem deficiência na procura de orientação nos serviços de saúde por parte do paciente e/ou falhas no acesso e qualidade da assistência à saúde. Em nossa pesquisa, a taxa de sobrevida global dos pacientes em 5 anos foi de $38,71 \%$. No período de 1990 a 1992, em Curitiba, estudos mostraram que esta taxa global foi de $50,1 \%{ }^{7}$. Já estudos mais recentes ${ }^{18}(1982$ a 2002) realizados no Sudeste, na cidade de 
Ribeirão Preto, encontraram esta taxa sendo de $24 \%$, o que demonstra variabilidade na taxa global e mereceria outros estudos em outras regiões.

\section{Conclusões}

O carcinoma epidermóide mostrou ser mais freqüente no sexo masculino, na $5^{\mathrm{a}} \mathrm{e}$

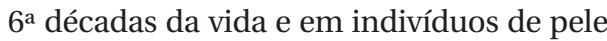
branca ou caucasianos. Atingiu mais precocemente o sexo feminino em relação ao masculino, porém com redução de freqüência no feminino no decorrer do período estudado. A região anatômica de maior freqüência foi a língua. Nosso estudo demonstrou uma tendência de ocorrência dos estádios mais avançados da doença nos encaminhados por instituições públicas, referenciados por profissionais médicos e com nível de instrução até $01^{\circ}$ grau incompleto.

A maioria dos que se concentravam no estádio T4 evoluiu para o óbito (63,04\%). A taxa global de sobrevida em 5 anos foi de $38,71 \%$, e o tempo mediano de sobrevida foi de 23 meses. É necessária uma maior atenção ao câncer bucal nessa população, com intervenção dos profissionais de saúde e órgãos públicos para que se possa estabelecer o diagnóstico precoce dessas neoplasias para o tratamento.

\section{Referências}

1. Ministério da Saúde, Instituto Nacional do Câncer Condutas do Inca/MS. Head and neck epidermoide carcinoma. Rev Bras Cancerologia 2001; 47(4): 361-76.

2. Tommasi A F. Diagnóstico em Patologia Bucal. $1^{\mathrm{a}} \mathrm{ed}$. SãoPaulo: Livraria Editora Artes Médicas; 1982.

3. Abdo EN, Garrocho AA, Barbosa AA, Oliveira EL, FrançaFilho L, Negri SLC et al. Time elapsed between the first symptoms, diagnosis and treatment of oral cancer patients in Belo Horizonte, Brasil. Med Oral Patol Oral Cir Buca. 2007; 12(7): 469-73.

4. Costa ALL, Pereira JC, Nunes AAF, Arruda M LS. Correlation between TNM classification, histological grading and anatomical location in oral squamous cell carcinoma. Pesqui Odontol Bras 2002; 16(3).; 216-20

5. Dedivitis RF, França CM, Mafra ACB, Guimarães FT, Guimarães AV. Características clínico-epidemiológicas no carcinoma espinocelular de boca e orofaringe. Rev Bras Otorrinolaringol 2004; 70(1): 35-40.

6. Aguiar MCF, Garrocho AA, Abdo EM. Perfil do paciente portador de carcinoma epidermóide da cavidade bucal, em tratamento no Hospital Mário Penna em Belo Horizonte. Rev Bras Cancerologia 2002 ; 48(3): 357-62.

7. Oliveira LR, Silva AR, Zucoloto S. Perfil da incidência e da sobrevida de pacientes com carcinoma epidermóide oral em uma população brasileira. J Bras Patol Med Lab 2006; 42(5): 385-92.

8. Franco E, Kowalski LP, Oliveira BV, Curado MP, Pereira RN, Silva ME et al. Risk factors for oral cancer in Brazil: a case control study. Int J Cancer. 1989; 43: 992-1000.
9. Queiroz RC. Validade e confiabilidade das declarações de óbito por câncer de boca no município do Rio de Janeiro [monografia na internet]; 2002. [Disponível em URL: http:// portalteses.cict.fiocruz.br/transf. php?script=thes_cover\&id=000032\&lng=pt\&nrm=iso [Acessado em 15defevereiro de 2007].

10. Marzola C, Medani EH, Campos CRN, Toledo- Filho JL, Oliveira MG. Oral Cancer - Incidence, Etiopatogeny, Diagnosis, Precancerous Lesions, Treatment and Prognosis. Revista ATO [periódico on line] 2006; 6(2). [Disponível em URL: http:/ /www.actiradentes.com.br/ revista/index.php] [Acessado em 13 de janeiro de 2008].

11. Ministério da Saúde. Instituto Nacional do Câncer. Neoplasias Bucais - Diagnóstico. Rio de Janeiro (RJ): Engenho e Arte; 2002.

12. Organização Mundial da Saúde; Organização Panamericana da Saúde. Classificação Estatística Internacional de Doenças e Problemas Relacionados à Saúde - Décima Revisão .8 ed. São Paulo: Editora da Universidade de São Paulo; 2000.

13. Hora IAA, Pinto LP, Souza LB, Freitas RA. Estudo epidemiológico do carcinoma epidermóide de boca no estado de Sergipe. Cienc Odontol Bras 2003; 6(2): 41-8.

14. Campos JLG, Chagas JFS, Magna LA. Fatores de atraso no diagnóstico do câncer de cabeça e pescoço e sua relação com sobrevida e qualidade de vida. Rev Bras Cir Cabeça Pescoço. 2007; 36(2): 65-8.

15. Brasil. Ministério da Saúde. Secretaria de Atenção à Saúde. Instituto Nacional de Câncer. TNM. Classificação de Tumores Malignos. Traduzido por Ana Lúcia Amaral Eisenberg. $6^{\text {a }}$ ed. Rio de Janeiro; 2004. 
16. Kligerman J. O câncer como um indicador de saúde no Brasil. Rev Brás Cancerologia [periódico on line]. 1999; 45(3). Disponível em URL: http://www.inca.gov.br/rbc [Acessado em 20 de fevereiro de 2007].

17. Kerdepon D, Sriplung H. Factors related to advanced stage oral squamous cell carcinoma in Southern Thailand. Oral Oncol 2001; 37(3): 216-21.

18. Ministério da Saúde. Instituto Nacional do Câncer. Estimativa 2008 - Incidência de câncer no Brasil [publicação on line]. Rio de Janeiro; 2008. Disponível em URL: http://www.inca.gov.br/estimativa/2008/index. asp?link=tbregioes_consolidado.asp\&ID=1] [Acessado em 2 de abril de 2008].

19. Ministério da Saúde.Fundação Nacional da Saúde. DATASUS. Indicadores de morbidade e fatores de risco- D.5 Taxa de incidência de neoplasias malignas [publicação on line]. Brasília: MS;2006 [Disponível em URL: http://tabnet.datasus.gov.br/cgi/idb2006/d05. htm] [Acessado em 15 de março de 2006].

20. Ministério da Saúde. Fundação Nacional de Saúde. DATASUS.. Sistema de Informações Hospitalares do SUS. Morbidade Hospitalar do SUS por local de residência - Brasil. [publicação on line] Brasília: MS; 2006. Disponível em URL: http://tabnet.datasus.gov. br/cgi/tabcgi.exe?sih/cnv/mruf.def [Acessado em 12 de agosto de 2006].

21. Ministério da Saúde. Fundação Nacional de Saúde. DATASUS. Sistema de Informações Hospitalares do SUS . Morbidade Hospitalar do SUS por local de residência - Minas Gerais [publicação on line] Brasília: MS; 2006. Disponível em URL: http:/ / tabnet.datasus.gov.br/cgi/ tabcgi.exe?sih/cnv/mrmg.def [Acessado em 12 de agosto de 2006].
22. Amorim AG, Amorim RFB, Freitas RA. Estudo Epidemiológico do carcinoma epidermóide oral: Análise de 85 casos. Odontologia Clín.-Científ [periódico on line]. 2002; 1(1). Disponível em URL: http://www.cro-pe. org.br [Acessado em 1 de março de 2006].

23. Abdo EN, Aguiar MCF. Papel do cirurgião-dentista no encaminhamento de pacientes com câncer bucal. Rev Bras Odontol 2003; 60(3): 205-07.

24. Kowalski ISG, Souza CP. Social Representations of relatives and patients with oral and oropharyngeal squamous carcinoma on the prevention and diagnosis of cancer. Acta Oncol Bras 2001. 21(1): 206-10.

25. Costa EG, Migliorati AC. Câncer bucal: Avaliação do tempo decorrente entre a detecção da lesão e o início do tratamento. Rev Bras Cancerologia 2001; 47(3): 283-9.

26. Antunes JLF, Toporcov TN, Wünsch-Filho V. Resolutividade da campanha de prevenção e diagnóstico precoce do câncer bucal em São Paulo, Brasil. Rev Panam Salud Pública 2007; 21(1): 30-6.

Recebido em: 15/10/07

Versão final reapresentada em: 23/07/08

Aprovado em: 10/09/08 